\title{
Influencing Factors on the Vestibular Function of Deaf Children and Adolescents - Evaluation by Means of Dynamic Posturography
}

\author{
Burkard Schwab* and Georgios Kontorinis
}

Department of Otolaryngology, Medical University of Hannover, Carl-Neuberg-Str. 1, D-30625 Hannover, Germany

\begin{abstract}
Objectives: Previous studies have shown that both motor exercises and vestibuloocular tests reveal a difference in the balance function of deaf and normal-hearing children and adolescents.

The purpose is to evaluate the influence on balance function of the hearing status.

Material and Methods: A total of 80 children and adolescents between the ages of 4 and 20 years were studied. Of these, 40 children were either deaf or severely hearing impaired. The remaining 40 were control subjects of equivalent age without hearing or balance impairment.

The EquiTest ${ }^{\circledR}$, a device used in computerized dynamic posturography, was employed for the investigations. Mean equilibrium and latency scores from both groups were compared using t-tests for unrelated random samples.

Results: The deaf children achieved significantly lower equilibrium scores and latency scores than the control group. A positive linear relationship exists between the age of the subjects and the equilibrium scores obtained. Gender, extent of hearing loss and cause of deafness have no significant effect on the balance function of the deaf children. Deaf subjects with normal caloric excitability achieved significantly higher equilibrium scores than those with vestibular deficits.

Conclusions: The results support the hypothesis that damage to the cochlea, whatever its cause, may also detrimentally affect the vestibular organ. They do not, however, exclude the possibility that the poorer balance proficiency shown by deaf children may have other possible causes, such as CNS damage.
\end{abstract}

The fact that equilibrium scores increase with increasing age can be seen as indicating the maturation of central nervous mechanisms involved in integrating the various sensory qualities in the sense of balance.

An improvement in vestibular function through special training appears plausible, although this would necessitate diagnosis at a very early stage.

Keywords: Equitest, balance, cochlear implant, vestibular organ, equilibrium score, posturography.

\section{INTRODUCTION}

Even before more detailed knowledge about the function of the vestibular organ became available, it was suspected that deaf patients might also have an impaired sense of balance. As early as 1895, for example, Bruck [1] described a difference in the "locomotive behavior of normal and deafmute children and adults".

With the aid of various motor exercises, other investigators also found a balance deficiency or motor developmental delay in deaf and severely hearing-impaired children [2-5].

Horak et al. (1988) compared the motor abilities of normal, hearing-impaired (hearing loss $>30 \mathrm{~dB}$ ) and learning-disabled children between 7 and 12 years of age; they also conducted (postrotatory) vestibular tests and posturographic tests (such as the EquiTest ${ }^{\circledR}$ ). The majority of

*Address correspondence to this author at the Department of Otolaryngology, Medical University of Hannover, Carl-Neuberg-Str. 1, D30625 Hannover, Germany; Tel: +49 (0)511/532-2469; Fax: +49 (0)511/532-5558; E-mail: schwab.burkard@mh-hannover.de the hearing-impaired children also exhibited vestibular deficits and, accordingly, performed more poorly in posturography testing [6].

Bearing in mind the close proximity of the cochlea and the vestibular apparatus (also in terms of innervation and vascular supply) it appears plausible that, whatever the cause of damage to the cochlea, the same agent could probably also damage vestibular structures. This hypothesis is supported by studies which show that vestibular dysfunction has a high frequency (up to $80 \%$ ) in children with severe hearing impairment [7-13]. The methods used involved assessment of either postrotatory or caloric nystagmus. In some cases parallels were discovered between the extent of hearing loss (and/or the etiology) and the vestibular function, but no absolute correlation was found.

Previous investigations into the difference between the balance function of deaf and normal-hearing children are, therefore, generally restricted to general motor abilities and vestibuloocular tests.

Simple motor exercises (i.e. basic vestibulospinal tests) do not, however, allow the various components of balance to be assessed separately, and vestibuloocular tests evaluate 
only one aspect of the balance system, which may provide only little information about a patient's subjective impairment.

Development of the EquiTest $^{\circledR}$ means that an investigative tool is available which is capable of assessing balance under various simulated sensory conditions; rather than merely investigating vestibular function, it looks at balance from a more functional point of view.

Computerized dynamic posturography provides no information about the location of a lesion, and neither is the degree of impairment directly correlated with tests of vestibular function; the results do, however, correlate with the patients' own subjective perception of their impairment [14].

The only previous study on deaf children using CDP was by Horak et al. (1988). This study is focused primarily on hearing-impaired and learning-disabled children. For the EquiTest $^{\circledR}$ normative values for clinical assessment are available only for patients aged 20 and upwards; however, the EquiTest ${ }^{6}$ system and comparable force platforms have been used by a number of authors to investigate unimpaired children [15-19]. These studies focused primarily on development-related changes in balance function.

The problem outlined above leads to the following fundamental question being raised:

What influence do age, gender, extent of hearing loss and etiology have on the balance function of deaf children?

\section{MATERIAL AND METHODS}

\section{Subjects}

A total of 80 children and adolescents took part in the study.

The test subjects were divided into two subgroups of equal size: a group of deaf or hearing-impaired children admitted for preliminary examination with a view to cochlear implantation $(\mathrm{CI})(\mathrm{n}=40)$ and a group of children with normal hearing and balance $(n=40)$.

Each of the two groups consisted of 17 males and 23 females. Only individuals between 4 and 20 years of age were included in the study.

In order, from the outset, to exclude the effects of the age variable when comparing the balance function of the two groups, so-called age-matched pairs were formed - i.e. two subjects differing in age by no more than 6 months at the time of the study.

Since normative data (i.e. standard scores with which the results obtained for all subjects are automatically compared) are only available for the EquiTest ${ }^{\circledR}$ device for the ages of 20 and above, subjects up to the age of 20 were included, even though these might perhaps be more accurately described as young adults than adolescents.

In addition, the data set for the analysis algorithms used by the EquiTest ${ }^{\circledR}$ system assumes a patient weight between 18 and $136 \mathrm{~kg}$ and a height between 76 and $203 \mathrm{~cm}$; these factors were also used as inclusion criteria.
The group of normal-hearing children and adolescents (the "normal subjects") consisted of 40 volunteers. Requirements for inclusion were the written consent of the parents, a subjectively normal hearing ability, and a history free from vestibular, neurological or musculoskeletal disorders.

The group of deaf or profoundly hearing-impaired subjects consisted of children and adolescents who were potential candidates for a cochlear implant.

All of these individuals had been admitted for a preliminary examination testing their suitability for cochlear implantation (subsequently referred to for convenience as CI children) or, in some cases, were in-patients at the Medical University of Hannover (MHH) awaiting cochlear implantation. Tests were, in all cases, conducted on the first day of hospitalization.

Inclusion was subject to the consent of both the child and the parents, who were also present during the tests.

Exclusion criteria were symptoms of giddiness, previous anesthesia and, as was the case for the normal-hearing children, neurological or musculoskeletal disorders.

In addition to the results of the EquiTest ${ }^{\circledR}$ assessment, further parameters were ascertained for the group of deaf and hearing-impaired children (hearing loss, results of vestibular tests, brainstem audiometry tests, cause of deafness). The data were obtained from the report on the CI preliminary examination or from the subject's anamnesis.

\section{Assessment using the EquiTest ${ }^{\circledR}$}

Assessments were carried out using the EquiTest ${ }^{\circledR}$ system EQ-EMG $^{\circledR}$ Version 5.06, Neurocom ${ }^{\circledR}$ International Inc., Clackamas, Oregon.

In computerized dynamic posturography (CDP) the subjects stand on a dual force-plate support surface. Force sensors register the vertical and horizontal (shear) forces exerted by the patients' feet.

The platform can either be moved parallel to the floor or tilted. The subject's field of view is restricted by a visual enclosure; this, too, can be inclined.

Subjects wear a safety harness during testing to prevent injury in the event of a fall.

The EquiTest ${ }^{\circledR}$ protocol consists of a sequence of balance exercises with an increasing level of difficulty.

The following tests are involved:

- $\quad$ the Sensory Organization Test (SOT);

- $\quad$ the Motor Control Test (MCT);

- the Adaptation Test (ADT).

In the Sensory Organization Test (SOT) the somatosensory and visual environments are systematically altered. "Sway referencing" can be used for the support surface and/or the visual surround so that both support and surround exactly follow the anteroposterior movements of the subject. Sway referencing leads to the subject receiving inaccurate orientational information for the eyes, feet and joints. 
The SOT involves testing under six different conditions (see Table 1), for each of which three 20 -second trials are carried out.

Table 1. Sensory Organisation Test

\begin{tabular}{|c|c|c|c|}
\hline Condition & Visual Surround & Support Surface & Subject's Eyes \\
\hline \hline 1 & Normal & Fixed & Open \\
\hline 2 & Normal & Fixed & Closed \\
\hline 3 & Sway referencing & Fixed & Open \\
\hline 4 & Normal & Sway referencing & Open \\
\hline 5 & Normal & Sway referencing & Closed \\
\hline 6 & Sway referencing & Sway referencing & Open \\
\hline
\end{tabular}

In the Motor Control Test (MCT) and Adaptation Test (ADT) a sequence of platform movements (MCT: translation = movement in a plane parallel to the floor; ADT: rotation about the horizontal axis) elicit automatic postural responses.

The Motor Control Test consists of three small, three medium and three large translational movements, first backwards, then forwards. The size of the translations is scaled to the subject's height.

In the Adaptation Test the amplitude of the rotational movements is the same for all trials and patients. The ankles are taken as the axes of movement. Five backward ("toes up") and five forward ("toes down") movements are performed.

The responses of the patient are measured and recorded.

\section{Equilibrium Score}

The equilibrium score is a measure of the subject's stability. It quantifies the extent to which sway motion under the various SOT conditions remains within the expected limits of stability.

A so-called composite equilibrium score is calculated from the determined scores (three trials per condition, i.e. 18 values). This involves adding one value achieved under each of conditions 1 and 2 (the mean of the three trials) and all three equilibrium scores for each of conditions 3-6. The total is then divided by 14 .

The composite score provides general information about the subject's ability to keep his or her balance.

\section{Sensory Analysis}

The second stage of analysis involves identifying which sensory quality is dysfunctional.

To this end the program calculates four quotients derived from the mean equilibrium scores for successive pairs of sensory sub-conditions (see Table 2).

\section{Strategy Score}

Following an external disturbance a spontaneous motor response occurs in order to maintain balance; this involves either the so-called ankle strategy and/or hip strategy.

In the ankle strategy, COG sway motion results from a rotational movement of the body about the ankles as a compact mass. No horizontal forces along the Y-axis are exerted on the support surface.

Hip movements, by comparison, which are normally accompanied by movements of the head and trunk, generate high shear forces.

The strategy score quantifies these movement strategies: subjects who largely apply the ankle strategy achieve scores approaching 100, whereas those who primarily adopt the hip strategy score lower.

When standing upright and motionless on the platform it is chiefly the ankle strategy that is applied, provided the COG is located within the limits of stability. The closer the COG approaches the stability limits, the more effective the hip strategy is in maintaining balance. The movement strategy is considered normal when there is a positive correlation between strategy and equilibrium scores.

\section{Latency}

In the Motor Control Test (MCT) the subject responds to the translational movements with an active swaying motion in the opposite direction.

This so-called active force response has to produce around twice as much torque as the swaying motion induced by the movement of the platform: half of this is needed to stop the induced swaying and the remainder is required in order to restore the body's equilibrium.

The time in milliseconds between the beginning of a translation movement and the onset of the subject's active force response is termed latency.

Latency values are determined by the computer for both feet separately using four separate algorithms derived from

Table 2. Sensory Analysis Derived from SOT Scores. The Results are Also Graphically Represented by the System

\begin{tabular}{|c|c|c|}
\hline Name & Quotient of SOT Conditions & Functional Relevance \\
\hline SOM Somatosensory & $2: 1$ & $\begin{array}{l}\text { Subject's ability to use input from the somatosensory system to maintain balance } \\
\text { (visual aids lacking) }\end{array}$ \\
\hline VIS Visual & $4: 1$ & $\begin{array}{l}\text { Subject's ability to use input from the visual system to maintain balance } \\
\text { (incorrect somatosensory information) }\end{array}$ \\
\hline VEST Vestibular & 5: 1 & $\begin{array}{l}\text { Subject's ability to use input from the vestibular system to maintain balance } \\
\text { (other information lacking or incorrect) }\end{array}$ \\
\hline
\end{tabular}


the force platform data; alternatively, they can be determined manually by the investigator by reference to standard MCT curves.

\section{Adaptation}

In the Adaptation Test (ADT) the subject is subjected to several uniform, randomly delayed $(3-5 \mathrm{sec}$.) sequential rotational movements of the support surface.

As the time delays differ in length, the subject is unable to predict the movements of the platform and is forced to react to the disruption by producing automatic postural responses.

The sway responses to the first rotation are usually longer than for the subsequent platform movements because subjects reduce their ankle resistance over the course of the trials. Balance is, as it were, maintained "with lesser exertion". The required input effort is reduced.

The adaptation score quantifies how well the subject adapts automatic movement responses to repeated movements of the surface, i.e. how well he or she can reduce sway (in both amplitude and duration) after several rotations.

This adaptive process describes a non-dimensional "sway energy" function which the program calculates for each individual trial.

The additional functions of the EquiTest ${ }^{\circledR}$ program - i.e. COG alignment during the Sensory Organization Test (SOT), and weight symmetry and response strength / amplitude scaling during the Motor Control Test (MCT) require no elaboration here as they are of little importance for the analysis.

No alterations were made to the EquiTest ${ }^{\circledR}$ equipment or to the prespecified sequence of the individual tests.

The "sway-referenced gain" feature was also left at the default setting, i.e. at 1.00. This means that when sway referencing is activated (see below) the support surface exactly follows the swaying of the subject rather than, say, swaying half as strongly or twice as strongly.

\section{Vestibular Tests}

In order to simplify the analysis, the results for the individual subjects (both the right and left ear) were assigned one of two broad categories: "normal excitability" or "abnormal excitability".

Nystagmus frequency following thermal excitation was categorized as follows: between 10 and 45 beats every 30 seconds $=$ normal thermal excitability; lower frequencies (i.e. between 0 and 10) = hypo-excitability; higher frequencies (i.e. above 45 ) = hyper-excitability.

\section{Brainstem Audiometry}

In four of the $40 \mathrm{CI}$ children the results of the brainstem evoked response audiometry (BERA) tests were not available. Responses were inducible in three children. The thresholds for these three subjects were, respectively, as follows: $90 \mathrm{~dB}$ for the right ear and $80 \mathrm{~dB}$ for the left; $90 \mathrm{~dB}$ for the left ear; $80 \mathrm{~dB}$ for the left ear.
In the latter two subjects no response could be triggered in the right ear; this was also the case for all the other children.

\section{Statistical Methods}

Statistical analysis was performed using the Statistical Program for Social Science (SPSS ${ }^{\circledR}$ ) for Windows ${ }^{\circledR}$, Student Version 10.0.

Since, owing to strong variance inhomogeneity, a multivariate test procedure could not be applied, T-tests for unrelated random samples were employed in order to compare means. The significance level was set at $5 \%$ $(\mathrm{p}<0.05)$.

In order to exclude age-related effects between the groups, so-called "age-matched pairs" were formed. The age distribution was approximately equal for both groups.

The first stage in analysis involved performing a further t-test to determine whether the gender of the subjects has an influence on the achieved composite scores.

Subsequently, the effect on balance function (here: the composite score) was investigated for the following factors: the effects of age on subjects (both groups), the extent of hearing loss, thermic excitability, and the cause of deafness (only CI children).

Depending on the nature of the available data, different procedures were selected for this purpose. For the variables of age and hearing loss (both quantitative, discrete) the method applied was linear progression, whereas for the variables of caloric excitability and cause of deafness (both qualitative, categorial) unifactorial ANOVA was chosen as a suitable procedure.

As only three children showed any response at all in BERA testing, these results could not be subjected to statistical analysis.

\section{RESULTS}

\section{Etiology}

The cause of deafness was unknown in $55 \%$ of the subjects.

In the category "prenatally acquired", deafness was due to rubella embryopathy in all three subjects. The five cases in the category "perinatally acquired" are attributable to hypoxia around the time of birth, and in the two cases of "postnatally acquired" deafness the cause was a measles infection or meningitis (see Fig. 1).

The mean composite scores differ between the various categories (see Table 3); it is noticeable that the later the onset of acquired deafness, the higher the composite scores that were achieved.

The differences are, however, not statistically significant $(\mathrm{p}=0.333)$.

Even when the results were broken down by causal category (congenital $v s$ acquired) this failed to yield statistical significance $(\mathrm{p}=0.114)$. 


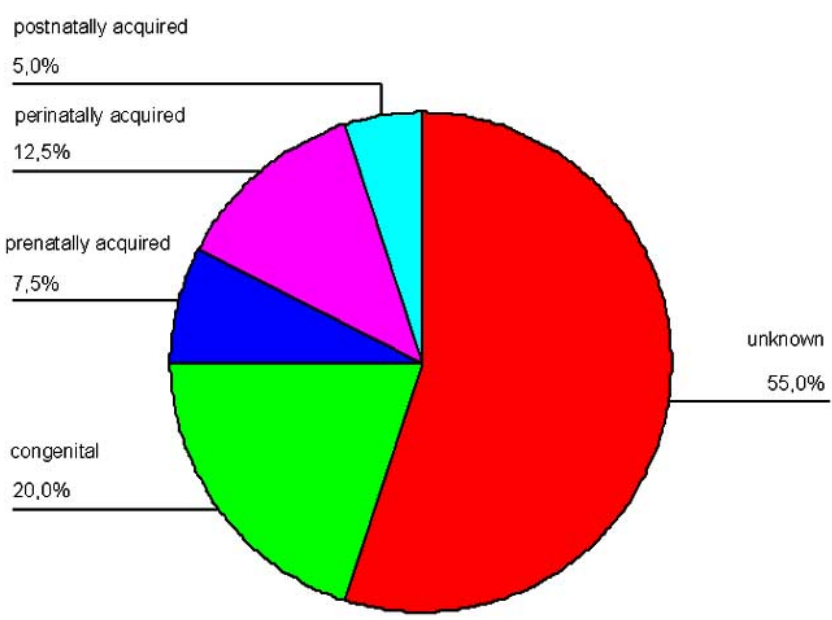

Fig. (1). Cause of deafness.

Table 3. Relation Between Composite Scores and Cause of Deafness

\begin{tabular}{|c|c|c|c|c|}
\hline Cause & N & Mean & $\begin{array}{c}\text { Standard } \\
\text { Deviation }\end{array}$ & $\begin{array}{c}\text { Standard } \\
\text { Error }\end{array}$ \\
\hline \hline Unknown & 22 & 49.18 & 16.81 & 3.58 \\
\hline Congenital & 8 & 42.88 & 21.91 & 7.74 \\
\hline Prenatally acquired & 3 & 62.00 & 22.61 & 13.05 \\
\hline Perinatally acquired & 5 & 57.00 & 16.90 & 7.56 \\
\hline Postnatally acquired & 2 & 65.50 & 4.95 & 3.50 \\
\hline Total & 40 & 50.68 & 18.28 & 2.89 \\
\hline
\end{tabular}

\section{Gender}

The 46 tested females achieved, on average, slightly higher composite scores (mean 65.28, standard deviation 15.35) than the 34 males (mean 56.94, standard deviation 20.90).

The difference fails, however (albeit by a small margin) to attain statistical significance: $\mathrm{p}=0.054$.

\section{Age}

Age effects between the groups had already been ruled out by the experimental design.

For the entire sample $(n=80)$ a weakly positive linear dependency was found between the age of the subject and the equilibrium scores achieved; the correlation coefficient $(\mathrm{R})=0.39$.

If the two groups are considered separately, $\mathrm{R}$ equals 0.547 for the deaf subjects and 0.424 for those with normal hearing.

It can be seen that the composite scores achieved by the CI children show much wider scatter. Children do, however, appear to improve faster with increasing age, although on average the performance remains below that of the subjects with normal hearing (see Fig. 2).

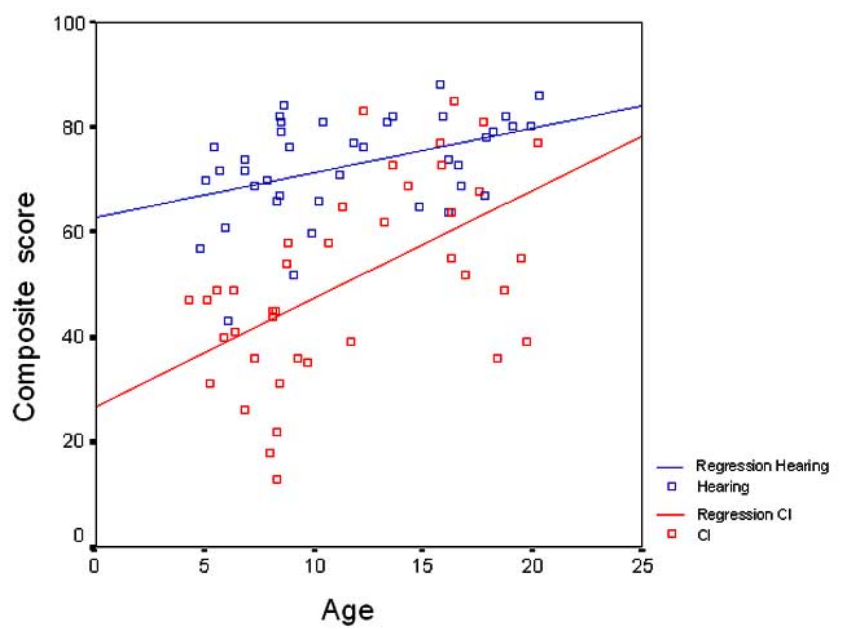

Fig. (2). Correlation between age and composite score (for deaf and hearing children).

\section{Hearing Loss in $\mathrm{dB}$}

The extent of hearing loss has no demonstrable influence on the equilibrium score $(\mathrm{p}=0.961)$.

All children in the CI group showed profound hearing impairment, with hearing loss in $\mathrm{dB}$ between 60 and 100: 60 $\%$ of individuals had hearing loss above $95 \mathrm{~dB}$.

\section{Thermal Excitability}

Around half of the children showed a normal response in the caloric test; excessive excitability (on the left side) occurred in only two subjects, whereas for the remainder the responses were either weak or non-existent (see Tables 4-6). In seven of the 40 individuals no caloric testing was carried out.

Table 4. Caloric Test (Left)

\begin{tabular}{|c|c|c|c|c|}
\hline & & Frequency & Percent & Valid percent \\
\hline \hline \multirow{3}{*}{ Valid } & Normal & 17 & 42.5 & 51.5 \\
\cline { 2 - 5 } & Hyper-excitable & 2 & 5.0 & 6.1 \\
\cline { 2 - 5 } & Hypo-excitable & 14 & 35.0 & 42.4 \\
\cline { 2 - 5 } & Total & 33 & 82.5 & 100.0 \\
\hline Missing & System & 7 & 17.5 & \\
\hline Total & & 40 & 100.0 & \\
\hline
\end{tabular}

Table 5. Caloric Test (Right)

\begin{tabular}{|c|c|c|c|c|}
\hline & & Frequency & Percent & Valid Percent \\
\hline \hline \multirow{3}{*}{ Valid } & Normal & 20 & 50,0 & 60.6 \\
\cline { 2 - 5 } & Hypo-excitable & 13 & 32.5 & 39.4 \\
\cline { 2 - 5 } & Total & 33 & 82.5 & 100.0 \\
\hline Missing & System & 7 & 17.5 & \\
\hline Total & & 40 & 100.0 & \\
\hline
\end{tabular}


Table 6. Thermal Excitability (Total)

\begin{tabular}{|c|c|c|c|c|}
\hline \multirow{3}{*}{ Valid } & $\begin{array}{c}\text { Abnormal } \\
\text { excitability }\end{array}$ & 16 & 40.0 & 48.5 \\
\cline { 2 - 5 } & $\begin{array}{c}\text { Normal } \\
\text { excitability }\end{array}$ & 17 & 42.5 & 51.5 \\
\cline { 2 - 5 } & Total & 33 & 82.5 & 100.0 \\
\hline \hline Missing & System & 7 & 17.5 & \\
\hline Total & & 40 & 100.0 & \\
\hline
\end{tabular}

The mean composite scores differ for the subgroups "normal thermal excitability" and "hypo- or hyperexcitability". The subjects who achieved a normal result in caloric testing also obtained higher equilibrium scores (see Table 7).

Table 7. Equilibrium Scores (Descriptive; for Normal vs Abnormal Thermal Excitability)

\begin{tabular}{|c|c|c|c|c|c|}
\hline & Caloric... & $\mathbf{N}$ & Mean & $\begin{array}{c}\text { Std. } \\
\text { Deviation }\end{array}$ & $\begin{array}{c}\text { Std. Error } \\
\text { |Mean }\end{array}$ \\
\hline \hline \multirow{2}{*}{ EQUI1 } & Abnormal excitability & 16 & 78.313 & 12.996 & 3.249 \\
\cline { 2 - 6 } & Normal excitability & 17 & 87.157 & 11.101 & 2.692 \\
\hline \multirow{2}{*}{ EQUI2 } & Abnormal excitability & 16 & 73.333 & 16.363 & 4.091 \\
\cline { 2 - 6 } & Normal excitability & 17 & 85.137 & 15.208 & 3.689 \\
\hline \multirow{2}{*}{ EQUI3 } & Abnormal excitability & 16 & 65.250 & 20.512 & 5.128 \\
\cline { 2 - 6 } & Normal excitability & 17 & 82.255 & 18.539 & 4.496 \\
\hline \multirow{2}{*}{ EQUI4 } & Abnormal excitability & 16 & 38.854 & 24.962 & 6.241 \\
\cline { 2 - 6 } & Normal excitability & 17 & 57.235 & 26.230 & 6.362 \\
\hline \multirow{2}{*}{ EQUI5 } & Abnormal excitability & 16 & 26.333 & 19.387 & 4.847 \\
\cline { 2 - 6 } & Normal excitability & 17 & 41.980 & 25.861 & 6.272 \\
\hline \multirow{2}{*}{ EQUI6 } & Abnormal excitability & 16 & 18.792 & 16.090 & 4.022 \\
\cline { 2 - 6 } & Normal excitability & 17 & 32.863 & 23.256 & 5.640 \\
\hline
\end{tabular}
$0.018)$.

The difference for the composite score is significant $(\mathrm{p}=$

Analysis of the differences between mean equilibrium scores for the six individual SOT conditions reveals that the differences are as follows: very weakly significant for conditions $1(\mathrm{p}=0.043), 2(\mathrm{p}=0.040)$ and $4(\mathrm{p}=0.048)$, significant for condition $3(\mathrm{p}=0.018)$ and not significant for condition $5(\mathrm{p}=0.059)$ and $6(\mathrm{p}=0.052)$.

\section{DISCUSSION}

The method chosen in order to compare the balance function of deaf and normal-hearing children was computerized dynamic posturography using the EquiTest ${ }^{\circledR}$. The advantages of this approach are its non-invasiveness and the fact that it emphasizes the functional aspects of equilibrium control. It is balance itself that is assessed, as opposed to merely the vestibular function [20].
Various studies have been conducted into the sensitivity and specificity of this method and its clinical benefits.

The authors differ rather widely in the conclusions drawn. A number of investigators consider dynamic posturography to be a suitable method for clinical diagnosis, referring to sensitivity values of $40 \%$ [21], approx. $50 \%$ $[22,23]$ and up to $95 \%$ [24].

Others are extremely critical of the method and cast doubt not only on its clinical benefit but also its validity. According to Dobie [25], no clinical population has yet been identified for which CDP consistently reveals disruptions or allows diagnoses - that would otherwise be missed, or for which the results of CDP would have led to the clinical treatment being substantially altered. CDP does not, therefore, meet the criteria for a meaningful clinical test, although this does not apply to its other uses in research, expert medical appraisals or rehabilitation.

Evans and Krebs [26] come to the conclusion that, although SOT results correlate moderately with the standard vestibuloocular tests, they show only a weak correlation with the authors' kinematic tests on dynamic stability under conditions of movement. They conclude that CDP is unsuitable for testing vestibulospinal function.

Keim [27] and Norré [28-30], in particular, point out that in clinical diagnostics CDP provides data that, while complementing the previous tests of vestibular function, do not render them superfluous. It cannot therefore supplant other test procedures.

A problematic aspect of these comparative studies is that, despite the multiplicity of different tests for investigating the vestibular organ, no "gold standard" exists.

The function of the sensory cells cannot be tested directly in vivo. The informative value of caloric testing is also limited, firstly because it is chiefly the horizontal semicircular canal that is influenced and, secondly, because the patient is assessed in a passive testing situation. Functional aspects can therefore be disregarded, because the patient is not required to actually balance.

With regard to the functional assessment of balance, even for the purposes of expert medical opinions and rehabilitation, CDP has now attained a certain status [27].

The recording of typical "balance patterns" using the EquiTest ${ }^{\circledR}$ simplifies the analysis of the results. It cannot, however, be used for children, owing to the lack of normative values.

Computerized dynamic posturography does, however, appear well able to provide useful information about functional differences in balance between deaf and hearing children.

\section{Influences on Balance Function}

\section{Gender}

Many previous studies have concluded that gender does not influence balance function. None of the following investigators found that gender influenced the performance of the children studied: Lindsey and O'Neal, Butterfield and 
Ersing, Siegel et al. and Rine et al., who investigated deaf and hearing-impaired children using motor tests [3-5, 31]; Potter and Silverman [9] and Gayle and Pohlmann [2], who also incorporated vestibuloocular function (postrotatory); and Foudriat et al. [16], who performed EquiTest ${ }^{\circledR}$ trials on normal 3-6 year-old children.

Only Riach and Hayes, who used a force platform to study the maturation of postural stability in children aged between 2 and 14 years, point out that although boys initially show greater instability than girls, they stabilize better and faster with age [18]. One conceivable cause might be the different patterns of play shown by girls and boys, with boys' play more dominated by physical activity which trains their sense of balance.

Overall, however, the influence of gender on balance function would appear to be negligible.

Age

There is a positive linear relationship between the subjects and the composite scores achieved.

This confirms the hypothesis that the sense of balance is subject to an age-dependent maturation process. The development of balance requires that all components continually develop and adjust, and above all that these different sensory impressions are integrated within the CNS, although the vestibular organ is already structurally and functionally complete by the time of birth [32].

Variation in the equilibrium scores achieved by the CI children is markedly higher than for the normal-hearing children, although the scores appear to increase more rapidly with increasing age in the CI children.

The latter trend could be attributable to the fact that, in addition to normal age-dependent improvement, compensation mechanisms also come into play which make up for vestibular deficits.

Overall, however, the scores obtained remain below the average scores of the normal-hearing children.

When interpreting the results, however, it must be remembered that the composite scores obtained by the group of deaf children show much greater variation than those of the control subjects.

Odendrick and Sandstedt, Riach and Hayes and Wolff et al. carried out studies involving, respectively, 64, 67 and 92 normal children and adolescents (up to 18 years of age) using various force platforms conceptually comparable with the EquiTest ${ }^{\circledR}$. All these investigators found that stability increased with age [18, 33, 34].

In two studies, normal subjects covering all age groups (7-81 and 6-90 years respectively) were tested using CDP; it was found that young and middle-aged adults are the most stable in terms of balance function, whereas children and older people sway more strongly [17, 35]. Foudriat et al. carried out EquiTest ${ }^{\circledR}$ trials on 82 normal children (3-6 years of age) and also concluded that postural stability increased with increasing age [16].

In studies by Butterfield and Ersing and by Siegel et al, in which hearing-impaired children (hearing loss $>60 \mathrm{~dB}$ ) aged between 3 and 14 were tested using a version of the
"Bruininks-Oseretsky Test of Motor Proficiency" which was restricted to balance exercises, it was found that postural stability consistently increased with age [5, 31].

Some investigators, however, stress that this trend follows not a linear but a gradual progression [16, 19]. According to Shumway-Cook and Woollacott, the period between the ages of 4 and 6 is a transitional phase before the ability to resolve multimodal sensory conflicts is fully in place. Not until the age of 7 do the children studied exhibit adult-like behavior in terms of postural control [19].

Forssberg and Nashner describe similar results. In their studies on normal children using apparatus similar to the EquiTest $^{\circledR}$, children younger than 7 to 8 years were unable to retain their balance when exposed to inconsistent visual or somatosensory sensations [15].

Peterka and Black report that, under the SOT conditions 4,5 and 6 , their subjects only obtained adult-typical scores at the age of 20 [17].

Although the vestibular system, proprioception and vision are functional at an early stage, the balance function can be optimized only when the maturation of the nervous system has reached an advanced stage and the postural stabilizing system has been "calibrated" by reciprocal tuning of the individual feedback systems.

\section{Hearing Loss}

The quantitative extent of hearing loss in the CI children has no demonstrable influence on the equilibrium scores achieved, although it must be pointed out that all these children in the study have profound hearing impairment.

Only the correlation between hearing loss and caloric testing was incorporated into certain studies, although no absolute correlation was found $[8,10,11,13]$.

Rosenblüt et al. investigated vestibular function in 107 deaf children. It emerged that the vestibular and auditory functions were not mutually independent, i.e. the greater the hearing loss, the greater the vestibular impairment. Hearing function was, however, classified on the basis of the type of audiometry curve and not assigned a definitive, quantified degree of hearing loss. It is striking that, in $16.1 \%$ of the children with relatively good auditory sensitivity, no vestibular responses were demonstrable, whereas normal responses occurred in $43.3 \%$ of the children with the poorest sensitivity. The authors conclude that although there is a correlation between auditory function and vestibular response, this link is not sufficiently clear-cut to allow predictions to be made on a case-by-case basis [10].

Sandberg and Terkildsen, who tested 57 severely hearing-impaired children, detected a tendency towards parallelism between hearing loss and vestibular function, but no absolute correlation. It is interesting that vestibular function proved normal in $80 \%$ of individuals with a hearing loss of less than $90 \mathrm{~dB}$, as opposed to only $20 \%$ of those whose hearing loss exceeded $98 \mathrm{~dB}$. Vestibular function appears, therefore, to be normal up to a point at which acoustic function has been almost entirely lost [11].

In the 25 hearing-impaired children studied by Swisher and Gannon, a vestibular response was present in $90 \%$ of cases. In the majority of these individuals there was a 
measurable bone-conduction auditory threshold, whereas no clear relationship was seen between positive vestibular response and the degree of air-conduction hearing loss. Then again, the loss of vestibular response was associated with a severe diminution of air-conduction hearing, whereas bone conduction in these cases was sometimes measurable and sometimes not. The authors conclude that the relationship between auditory and vestibular responses is of negligible importance when determining an individual's hearing loss [13].

Conversely, Brookhouser and Cyr noted that the extent of hearing loss is not a useful predictor of caloric hypoactivity. However, their 170 subjects were also profoundly hearing impaired; the quantitative differences in hearing loss were only slight [8].

We can conclude that the extent of hearing loss alone does not enable conclusions to be drawn about either vestibular function or dynamic balance performance in the EquiTest $^{\circledR}$.

\section{Caloric Excitability}

The subjects whom caloric testing revealed to have normal levels of excitability also achieved significantly higher composite scores.

Earlier investigations into vestibuloocular response (both rotatory and caloric) revealed that a large number of children with pronounced hearing loss also have deficient vestibular sensitivity.

Arnvig [7] found vestibular responses (both caloric and rotatory) in $41 \%$ of 468 children to be either absent or abnormal, as did Rosenblüt in $49 \%$ of 107 deaf children (caloric responses) [10]. Sandberg und Terkildsen divided their 57 subjects into three groups on the basis of average auditory threshold $(<90 \mathrm{~dB}, \quad 91-97 \mathrm{~dB},>98 \mathrm{~dB})$, with vestibular deficits (caloric) detectable in 20,50 and $80 \%$ of cases respectively [11]. Potter and Silverman observed hypoactive (postrotatory) vestibular responses in just under $60 \%$ of their test population, 34 deaf children [9] whereas Horak et al. (1988) cite a figure of $66 \%$ [6]. Selz et al. also describe a significant difference in the vestibular function of deaf and hearing children (with reference to rotatory tests) ([12].

Horak et al. (1988) report a strong correlation between VOR tests (postrotatory in this study) and performance in the SOT. The loss of vestibular function did not, however, affect motor properties such as coordination, strength or walking [6].

By contrast, Rapin describes a delay in motor development in some, but not all, children with limited vestibular function included in her study [36].

However plausible the connection between vestibular function and development of balance may seem, some questions pertaining to the effects of functional loss and the nature of compensation mechanisms remain unanswered.

\section{Cause of Deafness}

It is noticeable that the later the onset of acquired deafness, the higher the composite scores that are achieved.
The number of subjects in the individual subclasses was admittedly very small in some cases and the cause of deafness was unknown for more than half of the subjects. In these cases it is highly probable that deafness is either genetic in origin or due to a subclinical infection contracted during pregnancy $[7,37]$.

According to Arnvig and Rapin, loss of vestibular function in children is associated less often with a genetic cause than with acquired deafness [7, 36]. This is at odds with the above-mentioned result.

The only indisputable fact is that, in view of the ontogenic, anatomical and physiological proximity of the two organs, an agent that has a damaging effect on the inner ear could also have a detrimental impact on the vestibular organ. Whether it does, the extent to which it does, and how severely the overall balance function is impaired cannot, however, be predicted.

\section{CONCLUSIONS}

The results discussed above underline that there is a difference between the balance function of normal-hearing and deaf children which can be demonstrated using the EquiTest ${ }^{\circledR}$.

It can also be demonstrated that balance skills improve with age, although a number of deaf children can apparently compensate for their deficiencies better than others.

In view of the complexity of the task of standing upright and the various parameters that need to be evaluated, it is not surprising that the development of balance control continues into adolescence.

As expected, where vestibular failure was proven, this correlated with poorer balance control.

These facts support the view of several authors who claim that the ability to process sensory conflicts is not innate but must be learned by the child [15, 19]. This includes the ability to suppress misleading sensory information.

As the vestibular sensory impressions serve as a kind of reference with which the other sensory modalities are compared [38, 39], it is more difficult for children with vestibular deficits to maintain their balance when subjected to conflicting sensory perceptions.

Overall, however, gender and cause of deafness appear to have only a negligible influence on postural stability. The extent of hearing loss alone does not enable conclusions to be drawn about either vestibular function or dynamic balance performance in the EquiTest ${ }^{\circledR}$.

Fact is that, in view of the ontogenic, anatomical and physiological proximity of the two organs, an agent that has a damaging effect on the inner ear could also have a detrimental impact on the vestibular organ.

\section{REFERENCES}

[1] Bruck A. Über die Beziehungen der Taubstummheit zum sogenannten statischen Sinn. Pflugers Arch 1895; 59: 16-42.

[2] Gayle GW, Pohlman RL. Comparative study of the dynamic, static, and rotary balance of deaf and hearing children. Percept Mot Skills 1990; 70: 883-88. 
[3] Lindsey D, O'Neal J. Static and dynamic balance skills of eight year old deaf and hearing children. Am Ann Deaf 1976; 121: 4955 .

[4] Rine RM, Cornwall G, Gan K, et al. Evidence of progressive delay of motor development in children with sensorineural hearing loss and concurrent vestibular dysfunction. Percept Mot Skills 2000; 90: 1101-12.

[5] Siegel JC, Marchetti M, Tecklin JS, et al. Age-related balance changes in hearing-impaired children. Phys Ther 1991; 71: 183-89.

[6] Horak FB, Shumway-Cook A, Crowe TK, et al. Vestibular function and motor proficiency of children with impaired hearing, or with learning disability and motor impairments. Dev Med Child Neurol 1988; 30: 64-79.

[7] Arnvig J. Vestibular function in deafness and severe hardness of hearing. Acta Otolaryngol (Stockh) 1955; 4: 283-88.

[8] Brookhouser PE, Cyr DG, Beauchaine KA, et al. Vestibular findings in the deaf and hard of hearing. Otolaryngol Head Neck Surg 1982; 90: 773-77.

[9] Potter CN, Silverman LN. Characteristics of vestibular function and static balance skills in deaf children. Phys Ther 1984; 64: 1071-75.

[10] Rosenblüt B, Goldstein R, Landau WM, et al. Vestibular responses of some deaf and aphasic children. Ann Otol Rhinol Larnyngol 1960; 69: 747-55.

[11] Sandberg LE, Terkildsen K. Caloric tests in deaf children. Arch Otolaryngol 1965; 81: 350-355

[12] Selz PA, Girardi M, Konrad HR,et al. Vestibular deficits in deaf children. Otolaryngol Head Neck Surg 1996; 115: 70-77.

[13] Swisher LP, Gannon RP. A comparison of auditory and vestibular responses in hearing-impaired children. Acta Otolaryngol 1968; 66: 89-96.

[14] Ruckenstein MJ, Shepard NT. Balance function testing: a rational approach. Otolaryngol Clin North Am 2000; 33: 507-18.

[15] Forssberg H, Nashner LM. Ontogenetic development of postural control in man: adaptation to altered support and visual conditions during stance. J Neurosci 1982; 2: 545-52.

[16] Foudriat BA, Di Fabio RP, Anderson JH, et al. Sensory organization of balance responses in children 3-6 years of age: a normative study with diagnostic implications. Int $\mathbf{J}$ Pediatr Otorhinolaryngol 1993; 27: 255-71

[17] Peterka RJ, Black FO. Age-related changes in human posture control: motor coordination tests. J Vestib Res 1990; 1: 87-96.

[18] Riach CL, Hayes KC. Maturation of postural sway in young children. Dev Med Child Neurol 1987; 29: 650-58.

[19] Shumway-Cook A, Woollacott MH. Dynamics of postural control in the child with Down syndrome. Phys Ther 1985; 65: 1315-22.

[20] Furman JM. Posturography: uses and limitations. Baillieres Clin Neurol 1994; 3: 501-13.
[21] Asai M, Watanabe Y, Ohashi N, et al. Evaluation of vestibular function by dynamic posturography and other equilibrium examinations. Acta Otolaryngol Suppl 1993; 504: 120-24.

[22] Di Fabio RP. Sensitivity and specificity of platform posturography for identifying patients with vestibular dysfunction. Phys Ther 1995; 75: 290-05.

[23] Di Fabio RP. Meta-analysis of the sensitivity and specificity of platform posturography. Arch Otolaryngol Head Neck Surg 1996; 122: $150-56$

[24] Hamid MA, Hughes GB, Kinney SE, et al. Specificity and sensitivity of dynamic posturography. A retrospective analysis. Acta Otolaryngol Suppl 1991; 481: 596-00.

[25] Dobie RA. Does computerized dynamic posturography help us care for our patients? Am J Otol 1997; 18: 108-12.

[26] Evans MK, Krebs DE. Posturography does not test vestibulospinal function. Otolaryngol Head Neck Surg 1999; 120: 164-73.

[27] Keim RJ. Clinical comparisons of posturography and electronystagmography. Laryngoscope 1993; 103: 713-16.

[28] Norre ME. Sensory interaction platform posturography in patients with Meniere's syndrome. Am J Otolaryngol 1993; 14: 404-09.

[29] Norre ME. Sensory interaction posturography in patients with benign paroxysmal positional vertigo. Clin Otolaryngol 1993; 18 226-30.

[30] Norre ME. Sensory interaction testing in platform posturography. J Laryngol Otol 1993; 107: 496-01.

[31] Butterfield SA, Ersing WF. Influence of age, sex, etiology, and hearing loss on balance performance by deaf children. Percept Mot Skills 1986; 62: 659-63.

[32] Brandt T, Wenzel D, Dichgans J, et al. Die Entwicklung der visuellen Stabilisation des aufrechten Standes beim Kind: Ein Reifezeichen in der Kinderneurologie. Arch Psychiatr Nervenkr 1976; 223: 1-13.

[33] Odenrick P, Sandstedt P. Development of postural sway in the normal child. Hum Neurobiol 1984; 3: 241-44.

[34] Wolff DR, Rose J, Jones VK, et al. Postural balance measurements for children and adolescents. J Orthop Res 1998; 16: 271-75.

[35] Hytönen M, Pyykkö I, Aalto H, et al. Postural control and age. Acta Otolaryngol 1993; 113: 119-22.

[36] Rapin I. Consequences of congenital hearing loss - a longterm view. J Otolaryngol 1978; 7: 473-83.

[37] Walch C, Anderhuber W, Kole W, et al. Bilateral sensorineural hearing disorders in children: etiology of deafness and evaluation of hearing tests. Int J Pediatr Otorhinolaryngol 2000; 53: 31-8.

[38] Black FO, Wall C, III, Nashner LM, et al. Effects of visual and support surface orientation references upon postural control in vestibular deficient subjects. Acta Otolaryngol 1983; 95: 199-01.

[39] Black FO, Nashner LM. Vestibulo-spinal control differs in patients with reduced versus distorted vestibular function. Acta Otolaryngol Suppl 1984; 406: 110-14. 